\title{
PROCEEDINGS OF THE PATHOLOGICAL SOCIETY OF GREAT BRITAIN AND IRELAND
}

The 141st meeting of the Society was held at the University of Glasgow on 9, 10 and 11 July 1980

$$
\text { SYNOPSES OF PAPERS OF MICROBIOLOGICAL INTEREST }
$$

These synopses should not be cited as references in published work without the permission of the authors.

2. REDUCING ACTIVITY IN HUMAN MIXED NATIVE SALIVA AS DEMONSTRATED BY NITROBLUE TETRAZOLIUM

\author{
M. J. Kowolik \\ Department of Oral Medicine, University of Edinburgh
}

Human mixed native saliva (MNS) is a complex biological fluid with the potential for oxidation and for reduction reactions, but the resultant activity is reducing in nature, and has been attributed to glucose. Nitroblue tetrazolium (NBT) has been widely used as a marker of metabolic activity in phagocytic leucocutes by its reduction to a blue formazan.

Unstimulated MNS was incubated at $37^{\circ} \mathrm{C}$ with NBT $(0.3 \mathrm{mg} / \mathrm{ml})$, and a strong colour change occurred within $10 \mathrm{~min}$. Pure parotid saliva had no reducing activity as measured by this method. Both centrifugation and filtration, with a millipore filter pore size $0.25 \mu \mathrm{m}$ showed with subsequent testing that the reducing activity was localised to the solid fraction. The active fraction was non-dialysable and not associated with the epithelial cells, and lysis of the salivary neutrophils with distilled water did not diminish reaction intensity.

Aerobic culture of salivary bacteria and subsequent incubation with NBT indicated that activity is localised to gram-positive aerobic cocci in saliva. This was confirmed by the elimination of NBT reduction by pasteurisation, $2 \%$ chlorhexidine gluconate or benzyl penicillin. It may thus be necessary to consider the possibility of an artefact in the stimulated NBT test of neutrophil function if the test bacteria are capable of NBT reduction.

3. DEMONSTRATION OF BACTERIAL ANTIGENS IN WHIPPLE'S DISEASE BY THE IMMUNOPEROXIDASE TECHNIQUE

$$
\text { C. E. H. Du Boulay and D. H. Wright }
$$

\section{Department of Pathology, University of Southampton Medical School, Southampton General Hospital, Southampton SO9 $4 X Y$}

Formalin-fixed, paraffin-embedded, jejunal and lymph-node tissue from eight cases of Whipple's disease was obtained. By the immunoperoxidase technique, it was possible to identify bacterial antigens within the macrophages in the lamina propria of the jejunum and the lymph nodes. Various bacterial antisera were used in the study. Streptococcal antigens of Lancefield group B were consistently demonstrated in each case, although in some instances there was staining with more than one bacterial antigen. The possibility that this was due to cross-reacting bacterial antigens was discussed.

The distinctive and consistent pattern of staining obtained in these cases of Whipple's disease leads us to suggest that specific bacterial antigens are present in the macrophages of Whipple's 
disease. This may or may not have implications for the isolation and identification of a causative agent.

The immunoperoxidase technique has proved to be a useful tool in the demonstration of bacterial antigens in tissues.

\title{
4. THE VENEREAL TRANSMISSION OF INTESTINAL SPIROCHAETOSIS
}

\section{F. D. Lee and A. McMillan}

University Department of Pathology, Glasgow Royal Infirmary and Department of Sexually Transmitted Diseases, Black Street, Glasgow

Intestinal spirochaetosis is characterised by the colonisation of the surface epithelium of the large intestine and appendix by a micro-organism thought to belong to the genus Borrelia, and is readily identified in histological sections taken either from the appendix or from reactal biopsies. The incidence of this condition in the normal human population in the west of Scotland is estimated to be $4-10 \%$. Recently however a survey of rectal biopsies taken from practising homosexuals attending the Department of Sexually Transmitted Diseases in Glasgow has revealed an incidence of spirochaetosis of $37 \%$ which is significantly greater than that observed in any previous study of the condition. This observation indicates that the phenomenon of spirochaetosis is being transmitted by sexual contact and reveals the extent to which intestinal micro-organisms can be disseminated in this particular group of the population. Spirochaetosis seems however to be harmless; moreover it does not even protect the colon against other forms of infective disease, having been observed in association with other sexually transmitted conditions such as gonorrhoea and syphilis. It is also of interest that although spirochaetosis is readily eliminated by a topical application of antibiotics, it appears to be resistant to systemic antibiotic therapy.

\section{IMMUNE TOLERANCE TO DIETARY PROTEINS}

\author{
P. J. Gallagher, M. J. Gibney, N. J. Goulding, C. Pathirana and T. G. Taylor \\ Departments of Pathology and Nutrition, University of Southampton
}

Although a significant proportion of total dietary protein is absorbed intact, most adults have only low levels of circulating antibodies to food antigens. A chance finding in a feeding study in rabbits led us to explore the role of perinatal exposure in the induction of tolerance/ hyporesponsiveness to dietary proteins.

Food antibodies were measured by an enzyme-linked immunoabsorbent assay in rabbits reared from colonies fed with skimmed milk, fish meal or soya protein. At weaning, food-antibody levels were low in all groups. Half of the rabbits were then fed $20 \%$ soya diets for 1-4 months. Within 1 month antisoya antibodies were at least 10 times higher in animals from the fish-meal and milk groups but increased only slightly in rabbits from the soya colony. The remaining animals were fed $20 \%$ skimmed milk. Antimilk antibodies were substantially lower in rabbits derived from the milk as compared to the soya colony.

These results indicate that perinatal exposure to a dietary antigen may play an important role in the induction of tolerance/hyporesponsiveness to food protein. The possible mechanisms for this effect were discussed. 


\title{
6. WHATEVER HAPPENED TO LABORATORY-ACQUIRED HEPATITIS?
}

\author{
N. R. Grist
}

University Department of Infectious Diseases, Ruchill Hospital, Glasgow G20 9NB

The incidence of hepatitis in clinical laboratories fell abruptly after 1974 to a quarter (32 per 100000 person-years) of that for the previous 5 years (123). Follow-up showed that the true rates are even lower. This indicates that previous practices were unsatisfactory and capable of improvement. Improvement at that time could not be due to elaborate or expensive new "safety" measures. Hepatitis-B transmission in the laboratory occurs mainly by hand contact with contaminated items during processing of blood and serum; clean working procedures and the use of gloves suffice to control this. What little problems remain relate to haematology and biochemistry laboratories where these simple procedures are not always followed.

\section{HePatitis-B Surface antigen, hePatocellular Carcinoma AND CIRRHOSIS IN HONG KONG}

\author{
J. B. Gibson*, P. C. Wu*, J. C. I. Ho* and I. J. Lauder \\ Departments of Pathology* and Statistics广, University of Hong Kong
}

Aldehyde-fuchsin staining of liver tissue from necropsies in Hong Kong from 1963 to 1976 demonstrated hepatitis $\mathrm{B}$-antigen $(\mathrm{HBsAg}$ ) in $5 \%$ of deaths from causes unrelated to the viral infection; in $38 \%$ of 39 males with hepatocellular carcinoma (HCC) alone; in $62 \%$ of 131 males with cirrhosis alone; and in $83 \%$ of cirrhosis complicated by HCC in 158 males. This progression in incidence is statistically significant $(\mathrm{p}<0.0016)$. By applying these proportions to the total mortality in Hong Kong, it appears that a male dying in 1975 who was HBsAg positive was six times more likely to have HCC without cirrhosis than a comparable individual who was HBsAg negative. The corresponding risk factor for cirrhosis alone was $16: 1$; and for cirrhosis with $\mathrm{HCC}$ it was $50: 1$.

HBV was the only aetiological factor identified in $70 \%$ of the 496 cases of cirrhosis of both sexes; other agents, including alcoholism, accounted for 3\%; cirrhosis was cryptogenic in $27 \%$.

The incidence of persistent carriage of HBV in the healthy population of Hong Kong is high and this is the dominating aetiological association of $\mathrm{HCC}$ with or without cirrhosis.

\section{ThE CYTOPATHOGENICITY OF NON-PATHOGENIC SPECIES OF NAEGLERIA IN MAMMALIAN CELL CULTURES}

\section{Thomas Brown \\ Department of Bacteriology, University of Aberdeen}

Naegleria fowleri, the causative agent of acute primary amoebic meningoencephalitis, is highly cytopathogenic in vitro, and earlier studies revealed that trophozoites destroy cultured mouse-embryo (ME) cells simply by phagocytic activity. Because phagocytosis is a property of all amoebae, these findings prompted a detailed investigation of the behaviour of non-pathogenic species of Naegleria in cell cultures.

$N$. gruberi strain B1518/1c, confirmed to be non-pathogenic in mice, failed to cause cytopathic effects in a wide range of cell cultures at $37^{\circ} \mathrm{C}$. At $30^{\circ} \mathrm{C}$, however, the organism was vigorously cytopathogenic and destroyed the mammalian cells more quickly than did $N$. fowler $i$ at the same temperature. The cytopathic effects induced by $N$. gruberi in ME cells appeared identical to that caused by the pathogenic species and was characterised by gradual loss of mammalian cell cytoplasm. Studies by immunofluorescence and electron microscopy demonstrated that trophozoites destroyed individual ME cells by piecemeal engulfment of host-cell 
cytoplasm. Finally, 8 of 10 additional strains of Naegleria, isolated or acquired from various sources, were likewise cytopathogenic in $\mathrm{ME}$ cells at $30^{\circ} \mathrm{C}$ but not at $37^{\circ} \mathrm{C}$.

It was concluded that non-pathogenic species of Naegleria do not differ fundamentally from $N$. fowleri in lacking a specialised cytopathic mechanism, but can destroy mammalian cells in vitro given appropriate culture conditions. These findings are consistent with the view that cytopathogenicity of Naegleria is merely an expression of phagocytic activity-a basic attribute of all amoebae-and that $N$. fowleri is distinguished by its ability to exhibit this activity at mammalian body temperatures.

\title{
10. THE CELL-SURFACE ANTIGENS OF CLOSTRIDIUM DIFFICILE
}

\author{
Ian R. Poxton and Marie D. Byrne \\ Department of Bacteriology, University of Edinburgh Medical School, Edinburgh
}

Clostridium difficile has recently been shown to be involved in the aetiology of antibioticassociated pseudomembranous colitis. In an attempt to develop an immunological method for its detection by direct microscopy, and to examine the possibility of developing a serotyping scheme for $C$. difficile, the cell-surface antigens of $C$. difficile and related species have been investigated.

Two classes of antigens have been extracted: (i) with EDTA from whole cells and (ii) with $\mathrm{NaOH}$ from purified cell walls. EDTA antigens from 32 strains representing 10 species of Clostridium were examined in an enzyme-linked immunosorbent assay. The $C$. difficile antigen cross-reacted strongly with $C$. sordellii antiserum which had been raised against whole cells. Antigens prepared from $C$. sordellii and $C$. bifermentans also strongly cross-reacted with antiserum raised against $C$. difficile. The cross-reactive antigen has been visualised by crossed immunoelectrophoresis (CIE) and is shown to be a carbohydrate. The $\mathrm{NaOH}$-extracted antigen (the secondary wall polymer) of $C$. difficile has been isolated and visualised by CIE; its chemical composition has been determined, and its cross-reactivity with other clostridial antisera examined.

\section{TRansfer OF Plasmid-Mediated antibiotic Resistance IN BACTEROIDES SPP.}

\author{
V. O. Rotimi, B. I. Duerden and S. Hafiz \\ Department of Medical Microbiology, University of Sheffield Medical School, \\ Beech Hill Road, Sheffield
}

Transfer of plasmid-mediated antibiotic resistance was demonstrated between (i) members of the fragilis group of Bacteroides and (ii) between the B. fragilis group and strains of Escherichia coli. Clindamycin and erythromycin resistance was transferred joint ly from clinical isolates of $B$. fragilis to sensitive $B$. fragilis and $B$. distasonis strains. Chloramphenicol, erythromycin and tetracycline, and chloramphenicol + tetracycline resistance markers were transferred from donor strains of $B$. fragilis, $B$. thetaiotaomicron and $B$. ovatus to sensitive $B$. fragilis and $E$. coli strains but not to $B$. melaninogenicus or $B$. asaccharolyticus. Transfer required cell-to-cell contact, was not mediated by phage transduction and was not affected by the presence of DNAase. The $\mathbf{R}$ factors were transferred from the initial recipients to other sensitive strains of the $B$. fragilis group and $E$. coli and thence to $B$. fragilis again. Segregation of resistance markers occurred with selection for tetracycline resistance but not with selection for other markers. Transcipients were cured of multiple resistance by sub-inhibitory concentrations of aminoacridines and athidium bromide; cure of tetracycline resistance alone required prolonged incubation ( 21 days). Identical plasmids were demonstrated in the donors and transcipients by agarose-gel electrophoresis. 


\section{STUDY OF THE INTERACTIONS OF ANTIFUNGAL AGENTS AGAINST CANDIDA SPECIES BY A CONTINUOUS-CULTURE SYSTEM}

\section{T. R. Rogers and M. Petrou}

\section{Department of Medical Microbiology, Westminster Medical School, London SW1}

Conventional laboratory methods of testing the sensitivity of Candida and other fungi to antifungal drugs are unsatisfactory, because they may not adequately represent events occurring in vivo. In addition, the effect of combinations of agents, the use of which may be required in immunologically compromised patients, cannot be easily studied. A continuous-culture (chemostat) system has been established in which clinical isolates have been grown in pure culture. By a defined salt medium, constant flow rate and physiological $p \mathrm{H}$, the individual and combined activities of several antifungal agents, including amphotericin $B$ and members of the imidazole group, were investigated. The effect on total and viable counts was noted. The influence of variations in $p \mathrm{H}$, temperature and of protein binding were also assessed.

Preliminary results have shown that the exponential reduction in growth of the organism seen with individual drugs can be influenced by physiological factors, and can be modified in various ways by the addition of different drugs. These findings suggest that this system could be used for demonstrating antagonistic and synergistic interactions.

13. EFFECTS OF BENZYL PENICILLIN ON STRAINS

OF NEISSERIA GONORRHOEAE IN LIQUID MEDIUM

\section{S. Hafiz, J. J. Jamil and M. G. McEntegart}

Department of Medical Microbiology, University of Sheffield Medical School, Beech Hill Road, Sheffield S10 2RX

The effect of benzyl penicillin on strains of $N$. gonorrhoeae in liquid medium has been studied. Although the minimal inhibitory concentration of penicillin varies from strain to strain of $N$. gonorrhoeae (from 0.004 to $0.25 \mu \mathrm{g} / \mathrm{ml}$.) the lethal concentration for all non- $\beta$-lactamase producing strains appears to be the same, i.e., $0.5 \mu \mathrm{g} / \mathrm{ml}$. The interpretation of these findings was discussed.

14A ANTIFOlate baCterial CHEMOTHERAPY; ONE DRUG OR TWO?

\section{S. G. B. Amyes}

Bacteriology Department, University of Edinburgh Medical School, Edinburgh EH8 $9 A G$

When co-trimoxazole was first released in the United Kingdom 12 years ago, it was believed that the combination of trimethoprim and sulphamethoxazole was more effective than trimethoprim alone. It was claimed that the combination was synergistic and exerted a bactericidal response although the individual components were bacteriostatic. In addition, it was thought that the combination was able to delay the inevitable emergence of resistance.

In the treatment of urinary-tract infections, these beliefs are no longer valid. The demonstration of synergy is easily performed in vitro but is not evident in conditions similar to those found in the urinary tract. Although sulphamethoxazole is a bacteriostatic agent, trimethoprim is a bactericidal drug in its own right, even at concentrations far below those expected in the urinary tract. The additional presence of sulphamethoxazole does not promote trimethoprim activity. In Finland, until recently the only country to use trimethoprim alone, the percentage of trimethoprim-resistant isolates is not higher than that reported from some hospitals in Italy, France or the United Kingdom. Therefore, the use of trimethoprim alone for the treatment of urinary tract infections may be as effective as co-trimoxazole. 


\title{
14B. AN ASSESSMENT OF RECENT ADVANCES IN THE CHARACTERISATION OF ANAEROBIC BACTERIA
}

\author{
R. Brown, Marie Byrne, A. G. Fraser, G. Hay, Madeleine Ka Yee Ip, \\ I. R. Poxton and J. G. Collee \\ Department of Bacteriology, University of Edinburgh Medical School, \\ Edinburgh EH8 $9 A G$
}

The impact of developments such as the anaerobic cabinet and gas-liquid chromatography was considered in relation to evolving conventional approaches to the isolation and characterisation of clinically important anaerobes. The disadvantages of some biochemical and dyesensitivity tests were noted, and the continuing usefulness of antibiotic-disk resistance tests was confirmed. The limitations of enzyme studies and rapid growth approaches are conceded but neuraminidase research has provided evidence that may be of some taxonomic significance. Preliminary results on the location and determination of specific antigens at the cell surfaces of clostridia and bacteroides organisms hold much promise for the development of practical methods for identification at species level.

\section{EFFECT OF SOLUBLE IMMUNE COMPLEXES ON C2 SYNTHESIS BY HUMAN MONOCYTES}

\section{A. R. McPhadden, D. Lappin and K. Whaley \\ University Department of Pathology, Western Infirmary, Glasgow G11 6NT}

Human monocytes are know to synthesise many components of the complement system and to possess $F c$ receptors on their cell membranes. In immune-complex mediated diseases, such as SLE and RA, the increased synthesis rates of complement proteins could be due to such complexes acting on the $\mathrm{Fc}$ receptors on monocytes.

In the present study we have found that complement-free preparations of BSA/anti-BSA complexes formed at different antigen-antibody ratios enhanced $\mathrm{C} 2$ production by human monocytes maintained in continuous culture. Complexes formed at 2:1 antigen excess and at 4:1 antibody excess caused enhanced $C 2$ production whereas complexes formed at $8: 1$ antigen excess inhibited $\mathrm{C} 2$ production for the first 5 days of culture but enhanced production was found by day 7 . These effects were not due to immunoglobulin aggregates contaminating the immune-complex preparations.

The production of similar effects by immune complexes in vivo would result in an enhanced inflammatory response and would facilitate opsonisation and solubilisation of immune complexes.

\section{CyCliC NUCLEOTIDES MOdULATE COMPLEMENT BIOSYNTHESIS BY MONOCYTES}

\author{
D. Lappin and K. Whaley \\ University Department of Pathology, Western Infirmary, Glasgow G11 6NT
}

Intracellular levels of cyclic nucleotides control protein secretion from several cell types. We have investigated the role of cyclic nucleotides in the production of complement components by monocytes. Dibutyryl cAMP, theophylline, IBMX and cholera toxin all increase intracellular cAMP levels and all inhibited production of complement components by monocytes. The accumulation of radiolabelled intracellular protein in these cells showed that secretion of newly synthesised protein was impaired. Short-term pulse-label studies with ${ }^{3} \mathrm{H}$-labelled aminoacids showed that protein synthesis was also reduced and that the intracellular degradation of newly 
synthesised protein was increased. In contrast, the addition of dibutyryl cGMP enhanced the production of complement components.

Thus, the intracellular concentrations of cyclic nucleotides modulate the production of complement components by monocytes cultured in vitro. Pharmacological modulation of complement synthesis in vivo may be achieved by the use of agents that alter intracellular cyclic-nucleotide levels.

\title{
17. FACTORS INVOLVED IN MACROPHAGE ACTIVATION
}

\section{T. D. Brogan and Evelyn McNeil}

\section{Area Pathology Laboratories, Stockport and Departments of Bacteriology} and Virology, University of Manchester

Preparations of human polymorphonuclear leucocytes will ingest various test particles in the absence of serum, and the phagocytic behaviour of this type of cell is reproducible and predictable. In contrast, preparations of mouse peritoneal macrophages show considerable variation in their capacity to ingest the test particles in the absence of serum. Phagocytosis can be promoted by increasing the temperature and by adding serum to the medium. However, mouse macrophages can be "activated" by prior incubation with heat-inactivated serum and with serum fractions, and this treatment results in populations of cells with enhanced ability to ingest test particles in the absence of serum. Activation of mouse macrophages also takes place in vivo when the cells are harvested from mice bearing experimental tumours that give rise to ascites. Preliminary results showed that differences in ability to cause activation appear to exist between various serum components.

\section{Peroxidase-Positive Cells in the SPlenic White PUlP AND ANTIBODY RESPONSES IN ENDOTOXIN-SENSITIVE MICE}

\author{
J. M. Stark and B. Jasani \\ Departments of Medical Microbiology and Pathology, Welsh National \\ School of Medicine, Heath Park, Cardiff CF4 $4 X N$
}

Peroxidase-positive cells (PPC) are found in the white pulp of the mouse spleen after injection of bacterial endotoxin. These cells have the appearance of mononuclear phagocytes and are most numerous around the central arteriole. It has been postulated that the penet ration of these cells into this immunologically important area is related to the action of endotoxin as an immunological adjuvant. We examined this feature as well as antibody responses in animals rendered unusually sensitive to endotoxin by previous injection of BCG. The antibody response of mice was increased by BCG given 14 days beforehand and was accentuated by the addition of endotoxin ( $0.1 \mu \mathrm{g}$ intravenously). Parallel changes were found in the numbers of PPC in the splenic white pulp consistent with the idea that the likelihood of a positive immunogenic event is a function of the numbers of PPC passing through the white pulp.

\section{EFFECT OF TRYPANOSOMA BRUCEI PARASITAEMIA ON THE CIRCULATORY LEVELS OF A SUBSET OF T-LYMPHOCYTES IN THE GUINEA-PIG}

\section{R. G. White and J. B. Forrester}

Department of Bacteriology and Immunology, University of Glasgow

The changes in morphology and numbers of guinea-pig T-lymphocytes during the development and artificially induced regression of a parasitaemia with up to $10^{9}$ trypanosomes $/ \mathrm{ml}$ in the 
guinea-pig blood were described. The functional significance of these cells and their presumed proteoglycan product in immunological processes was discussed.

\title{
57. SERUM INHIBITORY FACTOR IN LEPTOMATOUS LEPROSY: ITS EFFECT ON THE PRE-S-PHASE CELL-CYCLE KINETICS OF MITOGEN-STIMULATED NORMAL HUMAN LYMPHOCYTES
}

\author{
M. M. Sherif, A. J. Robertson, R. C. Potts, J. H. Gibbs, \\ R. A. Brown and J. Swanson Beck \\ Departments of Pathology and Mathematics, University of Dundee
}

Study of 10 Egyptian men with long-standing lepromatous leprosy (mean duration $17 \cdot 4$ years) has shown that their sera inhibit mitogen-stimulation responses of normal human lymphocytes. When first tested, the sera partly inhibited the response to PHA and virtually abolished that to concanavalin A. After repeated freezing and thawing, the concanavalin inhibition disappeared whereas PHA was still partly inhibited. The sera did not inhibit PWM stimulation. The serum factor(s) had similar action on lymphocytes from six normal donors and they showed similar dose-response curves when tested against lymphocytes from one donor. The principal action of the sera was to reduce the number of cells responding to mitogen without modifying in any way the kinetics of recruitment or rate of volume growth during the $G_{1}$ phase.

Serum from 13 control patients did not modify the response of normal lymphocytes to stimulation by any of the three mitogens studied. It was concluded that the inhibitory factor(s) were a consequence of the disease and not of the environment and that they might contribute to the immunopathology of lepromatous leprosy.

\section{ANAEROBIC MENINGITIS WITH CAVERNOUS-SINUS THROMBOSIS}

\author{
B. I. Duerden, ${ }^{*}$ J. G. Yassa $†$ and L. S. Taitz† \\ Departments of Microbiology* and Paediatrics, $\dagger$ Children's Hospital, \\ Western Bank, Sheffield
}

Gram-negative anaerobic bacilli are rare causes of meningitis; most recorded cases were associated with otogenic brain abscesses and the commonest pathogen was Fusobacterium necrophorum (Bacteroides funduliformis). Lateral-sinus thrombosis is a recognised complication. Cavernous-sinus thrombosis is also rare in Britain; the commonest cause is staphylococcal infection derived from facial lesions; the mortality is around $30 \%$.

A 6-year-old boy presented with meningitis and cavernous-sinus thrombosis with a discharge from his perforated left ear drum. The spinal fluid contained 8000 white cells $/ \mu$, mostly polymorphs, and $F$. necrophorum was isolated in pure culture from the spinal fluid and blood culture and, with Haemophilus influenzae, from the ear. He was treated initially with penicillin and chloramphenicol and subsequently metronidazole; the organism was sensitive to all three. His level of consciousness was grade 4 with a right hemiparesis and right facial paralysis; a CAT scan showed extensive thrombophlebitis of cortical vessels over the left cerebral hemisphere but no brain abscess. The meningitis and cavernous-sinus thrombosis resolved slowly and the level of consciousness improved after 5-6 weeks; recovery of visual, motor, speech and cognitive functions progressed steadily during the following months. We present this previously unrecorded association of otogenic anaerobic meningitis and cavernous-sinus thrombosis. 